\title{
IOT based Smart Irrigation System
}

\author{
Srishti Rawal \\ Department of Computer Science, \\ VIT University
}

\begin{abstract}
Automation of farm activities can transform agricultural domain from being manual and static to intelligent and dynamic leading to higher production with lesser human supervision. This paper proposes an automated irrigation system which monitors and maintains the desired soil moisture content via automatic watering. Microcontroller ATMEGA328P on arduino uno platform is used to implement the control unit. The setup uses soil moisture sensors which measure the exact moisture level in soil. This value enables the system to use appropriate quantity of water which avoids

over/under irrigation. IOT is used to keep the farmers updated about the status of sprinklers. Information from the sensors is regularly updated on a webpage using GSM-GPRS SIM900A modem through which a farmer can check whether the water sprinklers are ON/OFF at any given time. Also, the sensor readings are transmitted to a Thing speak channel to generate graphs for analysis.
\end{abstract}

\section{Keywords}

Automation, Microcontroller, Arduino Uno, IOT, GSMGPRS SIM900A, Thing speak.

\section{INTRODUCTION}

Agriculture is the unquestionably the largest livelihood provider in India. With rising population, there is a need for increased agricultural production. In order to support greater

production in farms, the requirement of the amount of fresh water used in irrigation also rises. Currently, agriculture accounts $83 \%$ of the total water consumption in India [1]. Unplanned use of water inadvertently results in wastage of water. This suggests that there is an urgent need to developsystems that prevent water wastage without imposing pressure on farmers.

Over the past 15 years, farmers started using computers and software systems to organize their financial data and keep track of their transactions with third parties and also monitor their crops more effectively [2]. In the Internet era, where information plays a key role in people's lives, agriculture is rapidly becoming a very data intensive industry where farmers need to collect and evaluate a huge amount of information from a diverse number of devices (eg., sensors, faming machinery etc.) in order to become more efficient in production and communicating appropriate information [3]

With the advent of open source Arduino boards along with cheap moisture sensors, it is viable to create devices that can monitor the soil moisture content and accordingly irrigating the fields or the landscape as an when needed. The proposed system makes use of microcontroller ATMEGA328P on arduino uno platform and IOT which enable farmers to remotely monitor the status of sprinklers installed on the farm by knowing the sensor values thereby, making the farmers' work much easier as they can concentrate on other farm activities.

\section{LITERATURE REVIEW}

In A Remote Measurement and Control System for Greenhouse Based on GSM-SMS [4] the proposed system introduced a GSM-SMS remote measurement and control system for greenhouse based on PC-based database system connected with base station. Base station is developed by using a microcontroller, GSM module, sensors and actuators. In practical operation, the central station receives and sends messages through GSM module. Criterion value of parameters to be measured in every base station is set by central station, and then in base stations parameters including the air temperature, the air humidity.

Indu et al. (2013) [5] mainly focuses on reviews in the field of remote monitoring and control, the technology used and their potential advantages. The paper proposes an innovative GSM/Bluetooth based remote controlled embedded system for irrigation. The system sets the irrigation time depending on the temperature and humidity reading from sensors and type of crop and can automatically irrigate the field when unattended. Information is exchanged between far end and designed system via SMS on GSM network. A Bluetooth module is also interfaced with the main microcontroller chip which eliminates the SMS charges when the user is within the limited range of few meters to the designated system. The system informs users about many conditions like status of electricity, dry running motor, increased temperature, water content in soil and smoke via SMS on GSM network or by Bluetooth.

In [6], R.Suresh et al. (2014) mentioned about using automatic microcontroller based rain gun irrigation system in which the irrigation will take place only when there will be intense requirement of water that save a large quantity of water. These systems bring a change to management of field resource where they developed a software stack called Android is used for devices that include an operating system, middleware and key applications. The Android SDK provides the tools and APIs necessary to begin developing applications on the Android platform using the Java programming language. Mobile phones have almost become an integral part of us serving multiple needs of humans. This application makes use of the GPRS feature of mobile phone as a solution for irrigation control system. These system covered lower range of agriculture land and not economically affordable.

In IOT SMS alarm system based on SIM900A [7], an IOT alarm system based on SIM900A module of SIMCOM Company was designed for greenhouse. The system can gather environmental parameters such as air temperature and air humidity. Meanwhile, with the use of AT command, this system can also realize SMS automatic sending and receiving, environmental parameters overrun alarm and insufficient balance alarm. Through the system setting, the alarm message can be sent to the user-specified mobile phone automatically no matter what the users' location is. This system as a typical application of IOT in the agriculture has got some satisfactory results in the actual operation. 


\section{PROPOSED SYSTEM}

The system is a combination of hardware and software components. The hardware part consists of embedded system and software is the webpage designed using PHP. The webpage is hosted online and consists of a database in which readings from sensors are inserted using the hardware.

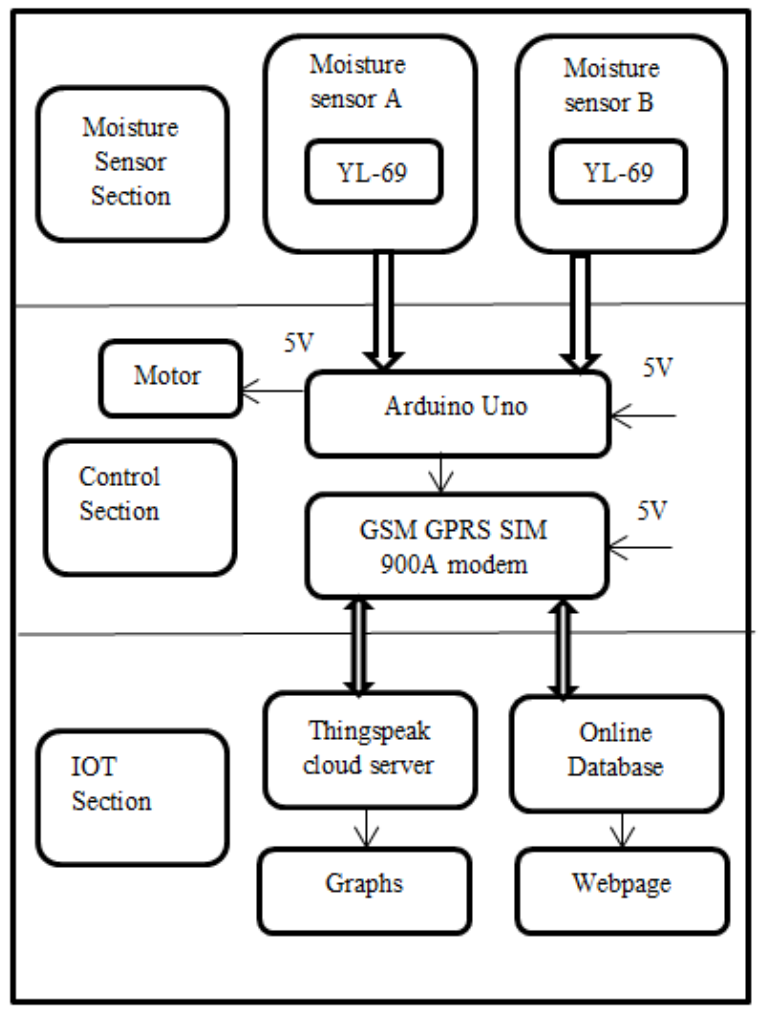

Figure 1: Overall Engineering Design

\subsection{Moisture Sensing Section}

Two YL-69 soil moisture sensors along with LM393 comparator modules were placed in different soil conditions for analysis. The sensor YL-69 is made up of two electrodes. It reads the moisture content around it. A current is passed across the electrodes through the soil and the resistance to the

current in the soil determines the soil moisture. If the soil has more water resistance will be low and thus more current will pass through.

On the other hand when the soil moisture is low the sensor module outputs a high level of resistance. This sensor has both digital and analogue outputs. Digital output is simple to use but is not as accurate as the analogue output. Since the Atmega 328P-PU microcontroller used for the Arduino Uno contains an onboard 10-bit 6-channel analog-to-digital (A/D) converter, the analog input pin of Arduino can read analog signals being sent from the sensor and return binary integers from 0 to 1023. Greater amount of output implies lesser moisture content.

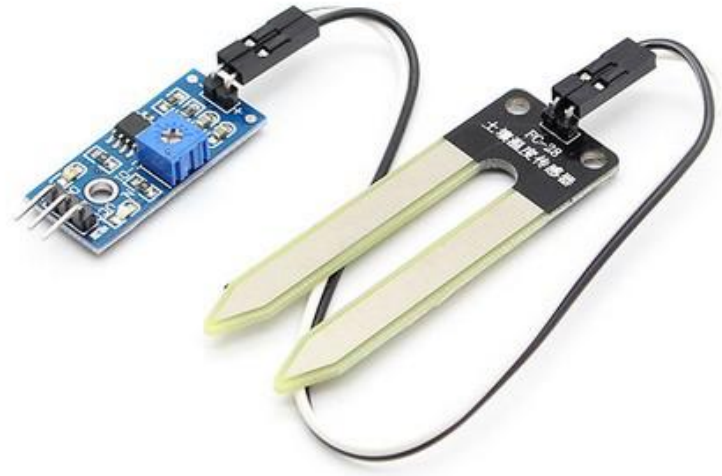

Figure 2 : Soil Moisture Sensing Unit

\subsection{Control Section}

Information from the sensors is transmitted to the arduino board. The arduino board consists of microcontroller ATMEGA328P which is responsible for controlling the switching on/off of the motor on which water sprinklers can be attached. Sensor values from arduino are transmitted to the GSM-GPRS SIM900A modem. A sim with $3 \mathrm{G}$ data pack is inserted into this modem which provide IOT features to the system. Values are further transmitted IOT section through the modem.

The GSM modem is a highly flexible plug and play quad bandSIM900A GSM modem for direct and easy integration to RS232 applications. It Supports features like Voice, SMS, Data/Fax, GPRS and integrated TCP/IP stack. The tx and rx pins from arduino are connected to the rx and tx of GSM modem respectively.

\subsection{IOT Section}

This section comprises of a webpage which displays the current water sprinkler status i.e. on or off and a button which redirects the user to a thing speak page which graphically depicts the sensor values.

\section{Moisture Sensor Values}

\section{Sensor A HIGH}

Pump A OFF

Sensor B HIGH

Pump B OFF

Refresh

CLICK HERE FOR GRAPHS!

Figure 3: Webpage showing sprinkler and soil moisture status

\section{METHODOLOGY}

Water sprinkler control was achieved by setting a threshold value at which irrigation should begin. When the sensors 
detect moisture content before the threshold, the sprinklers are switched on till the soil is completely moist. Figure 5 shows the flow chart of the system.

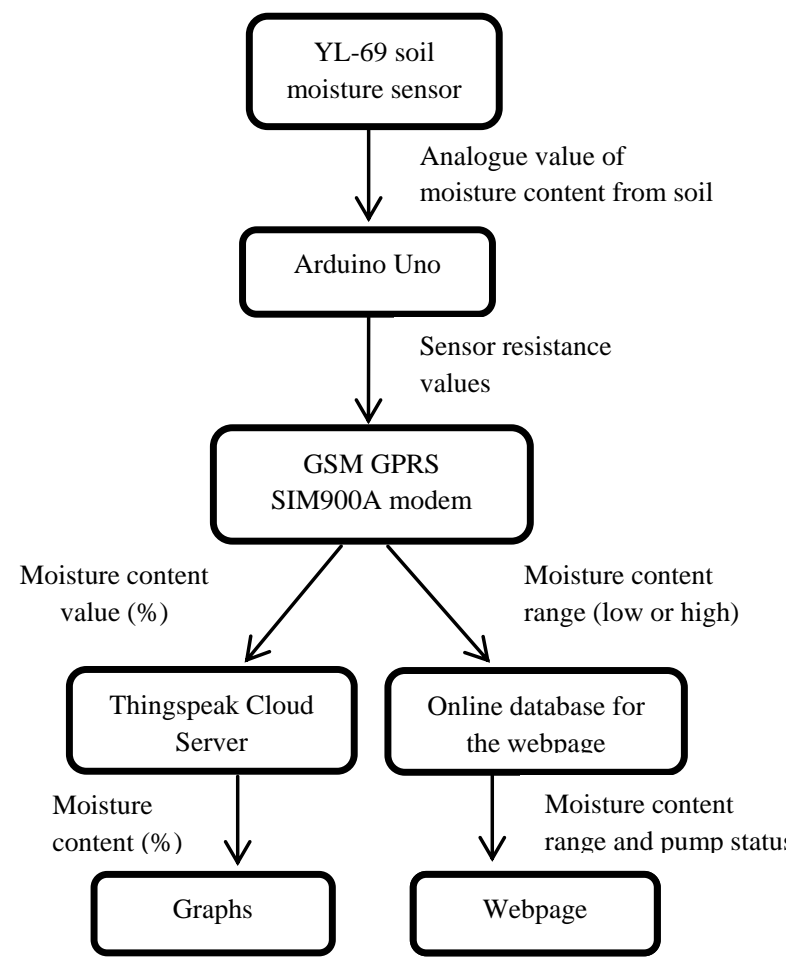

Figure 4 : Flow chart of the system

The hardware device comprises of moisture sensors, Arduino Uno and GSMGPRS SIM900A modem. The GSM modem is primary responsible for transmitting the data obtained from arduino to internet. This is done using AT commands which are depicted in the following table.

Table 1 : AT Commands

\begin{tabular}{|c|c|}
\hline Command & Meaning \\
\hline $\mathrm{AT}+\mathrm{CSQ}$ & Signal Quality Check \\
\hline AT+CGATT & $\begin{array}{l}\text { Attach or Detach } \\
\text { from GPRS support }\end{array}$ \\
\hline $\begin{array}{l}\text { AT+SAPBR }= \\
3,1,|" C O N T Y P E l ",| " G P R S \mid "\end{array}$ & $\begin{array}{l}\text { Setting the SAPBR } \\
\text { connection type to } \\
\text { GPRS }\end{array}$ \\
\hline $\begin{array}{l}\mathrm{AT}+\mathrm{SAPBR}= \\
3,1, \mathrm{l} \text { "APNI",l"airtel.gprs.coml" }\end{array}$ & $\begin{array}{l}\text { Setting the APN } \\
\text { string }\end{array}$ \\
\hline $\mathrm{AT}+\mathrm{SAPBR}=1,1$ & Setting the SAPBR \\
\hline $\begin{array}{l}\text { AT+HTTPPARA=|"URLl", } \\
\text { ।"http://smartfarmsiot.orgfree.com } \\
\text { ।" }\end{array}$ & $\begin{array}{l}\text { Setting the httppara, } \\
\text { website which needs } \\
\text { to be accessed }\end{array}$ \\
\hline AT+HTTPACTION=0 & Submit the request \\
\hline AT+CIPSEND & $\begin{array}{l}\text { Request initiation of } \\
\text { data sending }\end{array}$ \\
\hline
\end{tabular}

The information from sensors is transmitted to an online database from where it is used to display on a website. The webpage displays the moisture content in soil which has been divided into two categories : Low and High. Pump is to be switched on when the moisture content is low. The threshold values depend on the type of soil used.

Readings from the two sensors were also transmitted to a THINGSPEAK channel to obtain graphs. ThingSpeak is an open data platform and API for the Internet of Things that enables you to collect, store, analyze, visualize, and act on data from sensors or actuators, such as Arduino.

\section{RESULTS AND DISCUSSION}

The values obtained through sensors enable the system to switch the sprinkler on and off. A farmer can remotely monitor the irrigation process on the farm. Hence, the system contributed in making a smart farm. Table 2 depicts the readings of the two YL-69 soil moisture sensors taken over a period of one hour.

Table 2 depicts readings from two YL-69 soil moisture sensors one of which was inserted in over irrigated soil and the other in soil with initial moisture content $79 \%$. The readings were taken over a period of one hour to observe the rate at which moisture content in soil is reducing when the sprinklers are off. These readings are transmitted to the website and thingspeak channel. Figure 5 and 6 display the graphs plotted.

Table 2 : Sensor Readings

\begin{tabular}{|c|c|c|}
\hline Time (IST) & Sensor A(\%) & Sensor B(\%) \\
\hline $15: 53: 21$ & 79 & 100 \\
\hline $16: 00: 22$ & 74 & 100 \\
\hline $16: 11: 23$ & 70 & 100 \\
\hline $16: 16: 44$ & 69 & 100 \\
\hline $16: 30: 05$ & 67 & 100 \\
\hline $16: 34: 45$ & 66 & 100 \\
\hline $16: 43: 06$ & 65 & 98 \\
\hline $16: 48: 07$ & 65 & 97 \\
\hline $16: 56: 08$ & 64 & 95 \\
\hline $16: 59: 48$ & 63 & 93 \\
\hline $17: 00: 08$ & 63 & 93 \\
\hline $17: 05: 49$ & 62 & 92 \\
\hline
\end{tabular}

It can be observed from the graphs that moisture content of over irrigated soil takes longer period to reduce by $10 \%$ as compared to the moisture content of soil which is initially 79\% moist. Thus, the curve for sensor A is a continuously decreasing curve as the moisture reduces as time passes. For sensor B the moisture value initially is $100 \%$. The readings depict that sensor was in an over irrigated soil at the beginning. In our system possibility of over irrigation is avoided by turning the water sprinklers off as soon as the sensor reading is $100 \%$. 


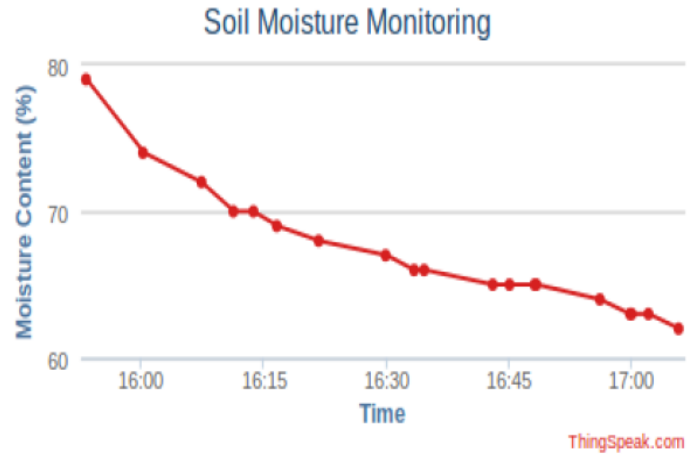

Figure 5. Graph of Sensor A : Inserted in initially 79\% moist soil

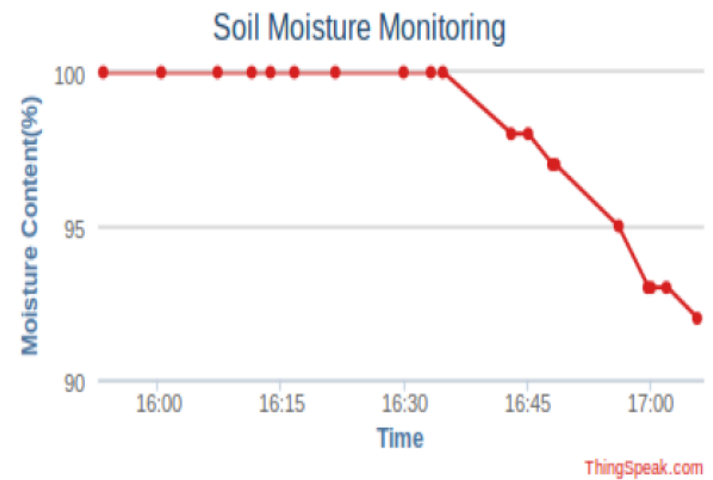

Figure 6. Graph of Sensor B: Inserted in over irrigated soil

\section{CONCLUSION}

A system to monitor moisture levels in the soil was designed and the project provided an opportunity to study the existing systems, along with their features and drawbacks. The proposed system can be used to switch on/off the water sprinkler according to soil moisture levels thereby automating the process of irrigation which is one of the most time consuming activities in farming. Agriculture is one of the most water-consuming activities. The system uses information from soil moisture sensors to irrigate soil which helps to prevent over irrigation or under irrigation of soil thereby avoiding crop damage. The farm owner can monitor the process online through a website. Through this project it can be concluded that there can be considerable development in farming with the use of IOT and automation. Thus, the system is a potential solution to the problems faced in the existing manual and cumbersome process of irrigation by enabling efficient utilization of water resources.

\subsection{Further Work}

To improve the efficiency and effectiveness of the system, the following recommendations can be put into consideration. Option of controlling the water pump can be given to the farmer i.e. he can switch on/off the pump in order to start/stop the process of irrigation without being present at the farm. The farmer may choose to stop the growth of crops or the crops may get damaged due to adverse weather conditions. In such cases farmer may need to stop the system remotely. The idea of using IOT for irrigation can be extended further to other activities in farming such as cattle management, fire detection and climate control. This would minimalize human intervention in farming activities.

\section{ACKNOWLEDGEMENT}

I would like to thank my guide Prof Sajidha SA who supported me through the different phases of the project. Also, I am grateful to VIT University for providing me the resources which led to successful implementation of the project.

\section{REFERENCES}

[1] Dr. Narayan G. Hegde, "Water Scarcity and Security in India", BAIF Development ReseachFoundation, Pune.

[2]Marvin T. Batte, "Changing computer use in agriculture: evidence from Ohio", Computers and Electronics in Agriculture, Elsevier science publishers, vol. 47, 1-13, 2005

[3] Csótó, Magyar, "Information flow in agriculture through new channels for improved effectiveness", Journal of Agricultural Informatics 1 (2), 25-34, 2010

[4] Jin Shen, Song Jingling, Han Qiuyan and Yang Yan, "A Remote Measurement and Control System for Greenhouse Based on GSM-SMS", Electronic Measurement andInstruments, 2007. ICEMI '07. 8th International Conference

[5] Indu Gautam and S.R.N Reddy, "Innovative GSM based Remote Controlled Embedded System for Irrigation", International Journal of Computer Applications Vol. 47 No.13, June 2012

[6] R.Suresh, S.Gopinath, K.Govindaraju, T.Devika, N.SuthanthiraVanitha, "GSM based Automated IrrigationControl using Raingun Irrigation System", InternationalJournal of Advanced Research in Computer and Communication Engineering Vol. 3, Issue 2, February 2014.

[7] Karan Kansara, Vishal Zaveri, Shreyans Shah, Sandip Delwadkar, and Kaushal Jani "Sensor based Automated Irrigation System with IOT: A Technical Review",(IJCSIT) International Journal of Computer Science and Information Technologies, Vol. 6 (6) , 2015 , 5331-5333

[8] Sumeet. S. Bedekar, Monoj. A. Mechkul, and Sonali. R. Deshpande "IoT based Automated Irrigation System", IJSRD - International Journal for Scientific Research\& Development| Vol. 3, Issue 04, 2015 | ISSN (online): 2321-0613

[9] K.S.S. Prasad, Nitesh Kumar, Nitish Kumar Sinha and Palash Kumar Saha "Water-Saving Irrigation System Based on Automatic Control by Using GSM Technology", Middle-East Journal of Scientific Research 12 (12): 1824-1827, 2012ISSN 1990-9233 c IDOSI Publications, 2012DOI: 10.5829/idosi.mejsr.2012.12.12.1258

[10] Remote Sensing and Control of an Irrigation System Using a Distributed Wireless Sensor Network by Yunseop (James) Kim, Member, IEEE, Robert G. Evans, and William M. Iversen, IEEE Transaction on Instrumentation and Measurement, VOL.57

[11] Thingspeak : https:// thingspeak.com/

[12] Alexandros Kaloxylos, Robert Eigenmann, Frederick Teye, Zoi Politopoulou, Sjaak Wolfert, Claudia Shrank, Markus Dillinger, Ioanna Lampropoulou, Eleni Antoniou, Liisa Pesonen, Huether Nicole, Floerchinger 
Thomas, Nancy Alonistioti, and George Kormentzas, "Farm management systems and the Future Internet era", Elsevier's Computers and Electronics in Agriculture 89 (2012) 130-144

[13] Pavithra D.S, M.S.Srinath GSM based Automatic Irrigation Control System for Efficient Use of Resources and Crop Planning by Using an Android Mobile
[14] ZHAI Shun, WANG Wei-hong, ZHANG Kan, LI Peng, IOT SMS alarm system based on SIM900A, School of Automation Science and Electrical Engineering,Beihang University,Beijing 100191,China

[15] Pei Suping, Wu Birui, The Soil Moisture Content Monitoring and Irrigation System Based on IOT, Journal of Agricultural Mechanization Research, 2013-07 